\section{$\underset{\substack{\text { hommes } \\ \text { \& migrations }}}{ }$}

\section{Hommes \& migrations}

Revue française de référence sur les dynamiques

migratoires

\section{$1322 \mid 2018$}

Exposer les migrations

\title{
Mohamed Mbougar Sarr, Silence du Chœur, Présence africaine 2017, 415 p., $18 €$.
}

\section{Mustapha Harzoune}

\section{(2) OpenEdition}

\section{Journals}

Édition électronique

URL : https://journals.openedition.org/hommesmigrations/6927

DOI : 10.4000/hommesmigrations.6927

ISSN : 2262-3353

\section{Éditeur}

Musée national de l'histoire de l'immigration

\section{Édition imprimée}

Date de publication : 1 juillet 2018

Pagination : 214-215

ISBN : 978-2-919040-42-1

ISSN : $1142-852 X$

Référence électronique

Mustapha Harzoune, « Mohamed Mbougar Sarr, Silence du Chœur, Présence africaine 2017, 415 p., 18 €. », Hommes \& migrations [En ligne], 1322 | 2018, mis en ligne le 01 juillet 2018, consulté le 21 janvier 2022. URL : http://journals.openedition.org/hommesmigrations/6927 ; DOI : https://doi.org/ 10.4000/hommesmigrations.6927 


\section{LIVRES}

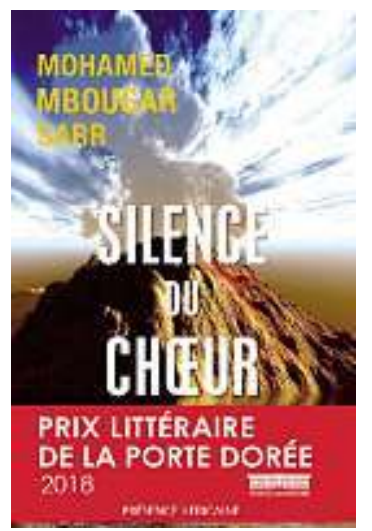

Mohamed Mbougar Sarr Silence du Chœur Présence africaine, 2017, 415 pages, 18 euros.

Voici enfin le livre qui donne à comprendre, sentir, toutes les dimensions et implications du départ et de l'arrivée en Europe d'hommes et de femmes qui réussissent à traverser l'Afrique et la Méditerranée. Sur le sujet, depuis Mahi Binebine (Cannibales, 1999) jusqu'à Jean-Paul Mari (Les Bateauxivres, 2015) ou Fawaz Hussain (Orages pèlerin, 2016), Silence $d u$ Chour est remarquable.

Remarquable par ses ambitions : réunir les destins, entremêler les vies de ceux qui débarquent et le quotidien de villageois siciliens, confrontés à l'imprévu, à l'étrange, à l'exceptionnel. Ills sont 72 rescapés africains recueillis par une association humanitaire. Tandis qu'ils attendent (s'impatientent) de connaître leur devenir administratif et juridique, le village se divise, se crispe : la suspicion et le rejet des uns grondent quand la lassitude, la crainte, gagnent les autres. Jusqu'au coup de théâtre final.

Le roman ne se contente pas de décrire le drame de l' "immigration clandestine " comme on disait hier, la "crise des migrants » comme on dit, non sans vulgarité, aujourd'hui, il dissèque le point, le lieu de la rencontre, le synapse sociologique et humain où se joue le devenir commun.

Remarquable par le foisonnement et l'acuité de ses analyses. II est question des injonctions à s'intégrer quand ce qui importe est de savoir, en insistant sur le " mieux", "comment mieux vivre ensemble ». II est question des fausses bonnes consciences humanistes et de ce que recouvre le mot « accueil ». II est question de la terrible mécanique de la défiance; de la facilité à céder à la paresse intellectuelle; de l'avilissement de la littérature et de l'art dans nos sociétés ; de cette honte qui ne doit plus s'abattre sur celui qui part, mais sur ce qu'une société inflige aux siens...

Remarquable par la justesse kaléidoscopique des descriptions, de l'exil, mais aussi des heurs et malheurs de l'hospitalité. L'auteur réussit à rassembler des personnalités et des psychologies diverses, à saisir inquiétudes et basculements. II montre les attentes, espoirs et frustrations des demandeurs d'asile, qu'il nomme les « ragazzi ». II montre l'engagement, les doutes, la fatigue de ceux qui décident de tendre la main. II montre les peurs et les certitudes de ceux qui entendent claquer la porte au nez de l'étranger.

Ce Silence du Chœu renforce la nécessité d'une révolution copernicienne qui viserait à faire de l'exil, du mouvement des hommes et des femmes, non la marge, le superfétatoire des existences et des devenir, mais le centre autour duquel gravitent toutes les autres composantes du « vivre ensemble».

À 28 ans, l'auteur maîtrise son sujet : il sait écrire. Construire. Capter. Il multiplie les genres : polar, journal, roman sociologique, intrigue politique, récit amoureux ou tragédie. Il excelle dans l'art de poser ses personnages, d'en faire, d'entrée, des êtres sensibles, réels, tourmentés. Ces nombreux personnages permettent, sans caricature, de balayer un spectre sociologique large : il y a un prêtre, un 
maire, des militants associatifs, des politiques, des artistes, un poète, un ci-devant rescapé devenu médiateur culturel. Et il y a ceux qui émergent du groupe des « ragazzi ».

"Le récit relate et relie » écrit Sarr. En ce sens et particulièrement, les littératures dites de l'exil ou de la migration aident à penser le monde, à résister en recomposant les imaginaires, en élargissant l'espace de l'entendement, des intui- tions, des sensibilités. Le Silence $d u$ Chœur permet de couvrir les bruits médiatiques, les peurs obsidionales, réelles ou entretenues, de déplacer les frontières des dépendances et interdépendances pour redéfinir notre conception du bien commun. Pour tenter de "rebâtir le monde, là où il s'effondre " et entendre, à nouveau, le chant d'un chœur commun.

M. H. 